\title{
Matchmaking and the multinational enterprise: how individual motivation and international strategy interact to affect expatriate adjustment
}

\author{
Catalin Ratiu* and Elena Lvina \\ John Molson School of Business, \\ Concordia University, \\ 1455 de Maisonneuve Blvd. W., Montreal, H3G 1M8, Canada \\ E-mail: C_Ratiu@jmsb.concordia.ca \\ E-mail: e_lvina@jmsb.concordia.ca \\ *Corresponding author
}

\section{Erica Berte}

Division of Business, Indiana University - Purdue University Columbus, 4601 Central Avenue, Columbus, IN 47203, USA

E-mail: eberte@iupuc.edu

\begin{abstract}
In this theoretical work, we propose a fresh look at expatriate adjustment, in which the focus is on the link between motivational antecedents and expatriate adjustment, moderated by international strategy orientation. Key concepts from human resource management and international strategic management are linked in a model that crosses levels of analysis and develops a typology of expatriate adjustment. The primary contribution of this paper is extending our understanding of human resource management in the complex environments of emerging and transitional economies, by showing when and how expatriates are likely to adjust more effectively.
\end{abstract}

Keywords: local-global dynamics; autonomous and controlled motivation; self-determination theory; international strategy; expatriate adjustment.

Reference to this paper should be made as follows: Ratiu, C., Lvina, E. and Berte, E. (xxxx) 'Matchmaking and the multinational enterprise: how individual motivation and international strategy interact to affect expatriate adjustment', Int. J. Human Resources Development and Management, Vol. X, No. Y, pp.000-000.

Biographical notes: Catalin Ratiu is a Lecturer in Strategic Management at the John Molson School of Business. He has previously held joint appointments at the universities of McGill and Concordia teaching international business and organisational policy courses. His research interests are in the areas of corporate strategies for sustainability and international management. He published in the Academy of Management Review, Management International, and International Journal of Business Strategy, wrote book chapters, and co-edited a book published by Routledge. His industry experience spans over eight years of legal and management consulting work in Europe and the USA. 
Elena Lvina is currently completing her $\mathrm{PhD}$ studies in Business Administration at the John Molson School of Business, Concordia University. She conducts research on organisational behaviour domains of leadership, political skill, teams and cross-cultural issues in management. Her research interest is reflected in her thesis, and several journal publications, including Personnel Psychology, International Journal of Group Tensions and International Journal of Entrepreneurship and Small Business. She also has expertise and considerable interest in teaching cross-cultural management.

Erica Berte received her PhD in Management from the University of São Paulo and Master's in Management from the Federal University of Santa Catarina, both from Brazil. Currently, she is an Assistant Professor of Management at the Indiana University - Purdue University Columbus. She has a large experience as a Trainer in Management, and more than 12 years in teaching in graduate and undergraduate programmes. Research interests include international business, cross cultural studies, expatriates and small technology business, in which holds several publications.

\section{Introduction}

How do managers succeed in their expatriate assignments? International assignments of managers are integral to multinational enterprises (MNEs) and whether managers adjust in their expatriate assignments has a tremendous impact on the organisation. In a business environment characterised by global, local (Levitt, 1983; Ohmae, 1990), or regional (Rugman, 2001) dynamics, the international specialised managers continue to be the cornerstone of multinationals, as corporations expand, merge and divest. Whether managers adjust and accomplish successfully their assignments becomes an important element to the functioning of the firm. The issue resonates with the entire firm, as a poor adjustment, or early termination of the assignment has severe cost implications (deValk, 2004), as high as three times the expatriate's annual domestic salary plus the cost of relocation (Kraimer et al., 2001). In addition, there is the indirect cost of the expatriate's lost of productivity. Failing an assignment can damage the expatriates' professional development and affect their self-confidence and leadership potential.

There is abundant knowledge on personal features that allow expatriates to succeed. Specifically, scholarship in this area has focused on individual antecedents to adjustment, specifically focusing on what contributes to individual's psychological comfort with new environment (Harrison et al., 2004). Nevertheless, we know far less about mechanisms that cross levels of analysis - individual to organisational - in the area of expatriate adjustment. Due to the complexity of conducting research across levels of analysis, there are almost no studies looking at individual characteristics in organisational contexts (Chen et al., 2010). Therefore, our understanding of this complex puzzle is still limited. Furthermore, the issue of adjustment is complicated by assignments in transitional and emerging economies, where the local context is dynamic and uncertain beyond any training available to the individual.

We tackle this challenge by proposing a multilevel theoretical model that explains how expatriates adjust effectively to their assignments depending on organisational context. Our interest therefore, is in the adjustment of managers in their expatriate assignments, and we attempt to understand: How do individuals' personal characteristics 
affect assignment success and firm performance depending on organisational characteristics? More specifically, we ask: how does individual motivation interact with international corporate strategy to affect expatriate adjustment.

The primary contribution of this paper is to the literature on international human resource management, where we propose a new understanding of a well known problem. We propose a model that extends existing knowledge of expatriate adjustment in several ways. First, we suggest and justify that motivational variables are significant and overlooked antecedents of expatriate adjustment. We rely on self-determination theory (SDT) to argue for their inclusion in studies focusing on international human resource management. Second, we bridge levels of analysis by proposing a moderating variable - international corporate strategy. We build on scholarship in the area of international management, specifically looking at local-global dynamics between multinational agents and emerging country actors, and show how the individual-level link between motivation and adjustment depends on organisational-level factors, such as strategy.

To support theoretical development in line with our research questions, the paper is organised as follows: In the first part, we review and organise the literature on expatriate adjustment. We also show how theories of self-determination and international corporate strategy offer necessary answers to unanswered questions. In the second part of the paper, we build theory drawing from these literatures, and propose a model of expatriate adjustment that includes motivation and international corporate strategy. Finally, we close we a discussion of theoretical and practical implications, along with directions for future research, suggesting ways in which scholars may use this model in their empirical designs.

\section{Adjustment, motivation and strategy}

We begin the discussion of expatriate adjustment in the context of multinationals interacting within emerging and transitional countries by organising the literature. As such, Figure 1 shows how scholars conceptualise the link between expatriate adjustment and firm performance. Extant literature on expatriate adjustment focuses on a variety of issues that help our understanding how expatriate managers adjust. In brief, the literature notes a number of antecedents and moderators to adjustment. Some scholars argue that managers' personal characteristics are important predictors of adjustment and success of the assignment (Black, 1990; Caligiuri, 2000). Others argue that, irrespective of personal characteristics, organisations have an important role in helping managers integrate in the local culture (Aycan, 1997). This integration is believed to moderate the chances of success of managers. Organisational support is seen as an important moderator (Lazarova and Calgiuri, 2001; Kraimer and Wayne, 2004), and it takes the form of mentoring (Feldman and Bolino, 1999), or offering family-inclusive packages (Black and Stephens, 1989; Caligiuri et al., 1998). The figure also highlights our extension of existing knowledge, by proposing motivational antecedents, and strategic orientation as moderator. 
Figure 1 Proposed extension of existing models of expatriate adjustment

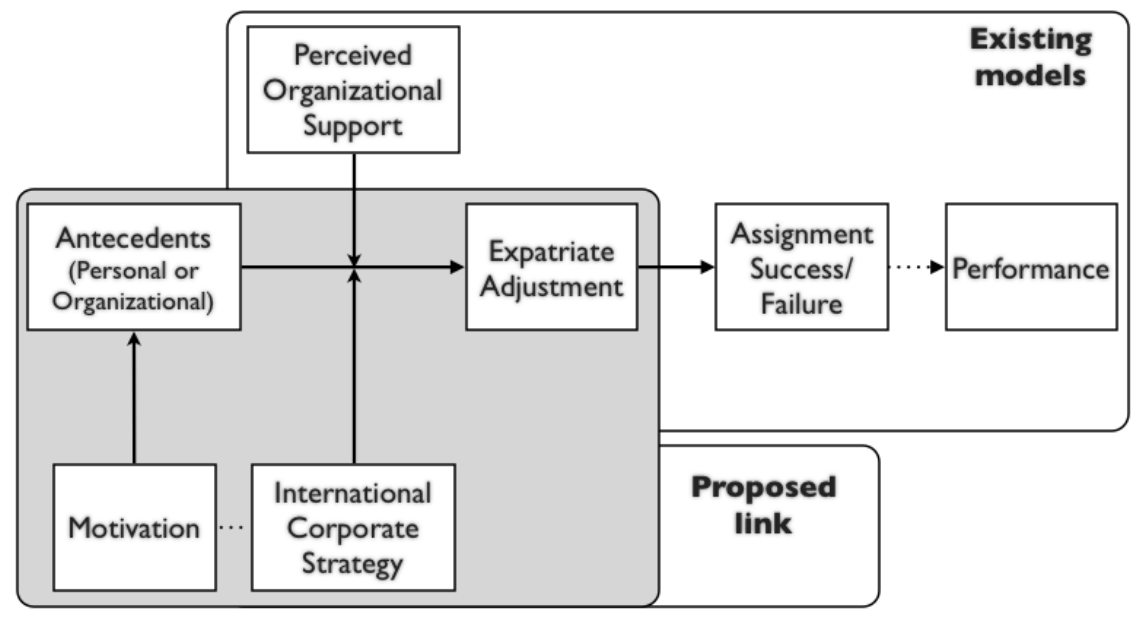

\subsection{Understanding expatriate adjustment}

We conceptualise expatriate adjustment as the extent to which individuals assigned to subsidiaries of MNEs outside their home territory achieve a desired fit with the local organisation and national culture such that they can perform their work duties in harmony with their environment. This definition builds on existing literature, where expatriate adjustment is seen as an affective psychological response to a new environment (Black, 1990), and the performance of a manager in a new setting (Kraimer and Wayne, 2004). Note that our definition focuses on the importance of an expatriate's social context (McGinley, 2008). We further model this definition through a necessary distinction between effective and ineffective adjustment, where effective adjustment represents the best fit, and ineffective adjustment represents a very poor or no fit.

The adjustment literature has further identified several dimensions of adjustment. Torbion (1982) proposes a holistic view. Black (1990) distinguishes between work and non-work factors, noting that the adjustment depended on the successful interaction with host nationals and the adjustment at work. This work is also echoed in the more recent article by McGinley (2008), who links adjustment of expatriates in Russia with social context variables, such as satisfaction with social contact with local nationals and instrumental coping support.

The premise upon which scholarly literature on expatriate adjustment is built is that effective adjustments lead to successful assignments, which in turn lead to higher firm performance (Gerhart, 2005). Conversely, terminated assignments are very costly (Caligiuri, 2000). Turnover cost for expatriate managers is, on average, higher than that for local or national managers, partly because the organisation invests more on the front end (Caligiuri, 2000; deValk, 2004). There is also evidence of the stressful effects of expatriation (Sanchez et al., 2000). The family plays an important role in the adjustment of the expatriate managers, and many managers claim that early termination was due to family related issues (Shaffer and Harrison, 1998; Shaffer et al., 1999, 2001). 
At the same time, the organisation can help through training before or during the assignment (Tung, 1981; Caligiuri et al., 2001). Previous assignment experience, language fluency, hierarchical level, and functional area, all have a strong influence on the adjustment process (Shaffer et al., 1999). Many researchers have studied antecedents of adjustment by looking at personality characteristics of the managers as predictors of adjustment. Most notably, Black (1990) and Caligiuri (2000) have found different aspects of the Big 5 personality characteristics to relate with expatriate adjustment.

To sum our understanding of expatriate adjustment, note how the focus so far is on various personality characteristics, which are generally assumed to change very little, if at all. A significant shortcoming of this research is that variables proposed as antecedents to adjustment are difficult to measure in practice, by human resource departments, and such tests are rarely administered effectively. Staffing practices are in dire need of more parsimonious models that allow them to assign the best candidates for any given assignment. Furthermore, personality-driven models have the shortcoming of not acknowledging the possibility that individuals may approach assignments differently, despite their personality not changing. Also the temporal dimension of personality traits is of concern, because it does not allow us to observe changes in managers before, during or after the assignment. Personality traits are assumed to change very little, if at all. To address this issue, we invoke the theory of self-determination. By looking at the motivation as antecedent to adjustment, we allow for changes in individual's preferences and performance depending on the context in which they operate.

\subsection{SDT: why and how motivation matters?}

In this section we introduce SDT and related concepts in an effort to justify its inclusion in the research and practice of international human resource management. Specifically, we argue that individuals' motivation related to an assignment is an overlooked, but critical variable to improve our understanding of why and how managers adjust more effectively and succeed in their assignments.

SDT as a theory of work motivation evolved from cognitive evaluation theory (CET: Deci, 1975; Deci and Ryan, 1980). Ryan et al.'s explained how extrinsically motivated behaviour can become autonomous, which, along with research on individual differences in causality orientations (Deci and Ryan, 1985b), led to the formulation of SDT (Deci and Ryan, 1985a, 2000; Ryan and Deci, 2000), which incorporated CET but is much broader in scope (Gagné and Deci, 2005). SDT incorporates CET's basic assumptions of the nature of human motivation: Humans are growth oriented, proactive, and inherently desirous of autonomous, or self-determined, functioning (as well as needing to be competent and related), while at the same time also being vulnerable to being controlled, coerced, or seduced by interpersonal or intrapsychic forces (Deci, 1992). Furthermore, SDT (Deci and Ryan, 1985a) gives content to motivation by focusing on three fundamental psychological needs - the needs for competence, relatedness, and self-determination (i.e., autonomy). The concepts of intrinsic and extrinsic motivation have also been incorporated into SDT.

Ryan and Deci (2000) define SDT as an approach to human motivation and personality that uses traditional empirical methods while highlighting the importance of individuals' evolved inner resources for personality development and behavioural self-regulation. SDT also claims to be concerned with the specific nature of positive developmental tendencies so "it examines social environments that are antagonistic 
toward these tendencies" [Ryan and Deci, (2000), p.69]. Thus, the stated focus of SDT is to specify the conditions that tend to support people's natural activity versus elicit or exploit their vulnerability to passivity. This is specifically relevant to emerging and transitional economies, which tend to accentuate the contextual sensitivities of individuals, and underscores the extremes of such behaviours.

SDT devotes considerable attention to detailing the contextual conditions that promote self-determined (versus. controlled) action by supporting people's autonomy. The theory proposed by Ryan and Deci suggests that there are different types of motivations or regulatory processes. Intentional behaviours differ in the extent to which they are self-determined versus controlled, the distinction being made by free choice as opposed to pressure by some external force. Essentially, choice regulates the processes that underlie self-determined behaviours. These behaviours have a perceived locus of causality that is internal to one's self. As Deci and Ryan (2000) put it, when self-determined, people are acting as origins of their own behaviour; when controlled, people are pawns to the coercive or seductive forces. In the first case it is an intrinsic motivational subsystem, in the second it is an extrinsic one. They further argue that, to maintain their intrinsic motivation, people need to feel competent and autonomous. Activities that are not interesting require extrinsic motivation, so perception of a contingency between the behaviour and a desired outcome (e.g., implicit approval or tangible rewards) becomes very important. However, if people experience satisfaction of the needs for relatedness and competence, they will tend to internalise external values and goals, which, in turn, will influence their behaviour, wellbeing and work outcomes.

\subsubsection{Internalised motivation: controlled versus autonomous motivation}

Internalisation refers to accepting ('taking in') a behavioural regulation and the value that underlies it (Gagné and Deci, 2005). The concept of internalisation first presented by Ryan et al. in 1985 (Ryan et al., 1985) addresses a differentiated analysis of extrinsic motivation. It postulates that the degree of satisfaction of the need for autonomy distinguishes external, introjected, identified, and integrated types of motivation. The behavioural regulation could be either controlled (performed in order to get an approval from relevant/ significant other), or autonomous (performed because of personal importance given to the particular behaviour). The distinction between the two is an important one as we look at global and local strategies employed by multinationals. Increasing internalisation and integration of behavioural regulation represents a transition from an external perceived locus of causality to an internal perceived locus of causality (Deci and Ryan, 1985b). To the degree that internalisation is accomplished, the individual moves away from heteronomy toward autonomy, or from external to self-regulation. As Ryan (1995) points out, many theorists emphasise the active, constructive nature of the internalisation process, as well as its tendency to be influenced by social contexts (Deci and Ryan, 1985b; Lepper, 1983; Loevinger, 1976; Schafer, 1968 as in Ryan, 1995). Strictly speaking, any intentional behaviour can be classified by the degree to which it is self-regulated versus regulated by forces outside the self, thus, indexing the relative integration of action (Ryan, 1995). Ryan and Deci (2000) provide a self-determination continuum of the types of motivation that vary from the non-regulated motivation through extrinsic motivation to intrinsically regulated intrinsic motivation (p.72). In this study we focus on the combination of external and introjected regulations 
(which represent controlled motivation), and identified and integrated regulations (which represent autonomous motivation).

\subsubsection{Controlled motivation as a combination of external regulation and introjection}

According to Williams and Deci (1996) and Ryan and Deci (2000) external and introjected regulations can be combined into a controlled motivation composite. Externally regulated behaviour is performed for an external reward or demand. This type of regulation is perceived as controlled, foreign or alienated. Introjection represents behaviour driven by the dynamics of self- and other approval and can be understood as a form of partial assimilation or integration (Ryan, 1995). Behaviour regulated through introjection is characterised by 'internally controlling states' (Deci and Ryan, 1985b) that are accompanied by the guilt and anxiety avoidance, as well as ego defence. This ego involvement is a key characteristic of this type of regulation. In this case, people act in order to maintain their feelings of worth. As Ryan and Deci (2000) put it "although internally driven, introjected behaviours still have an external perceived locus of causality and are not really experienced as part of the self” (p.72).

\subsubsection{Autonomous motivation as a combination of identification and intrinsic motivation}

According to Ryan and Deci (2000), some studies combine identified and integrated regulations with intrinsic regulation. This is combination is usually addressed as an autonomous motivation composite. Regulation through identification is a more autonomous, or self-determined, form of extrinsic motivation. It reflects a conscious valuing of a behavioural goal or regulation, such that the action is accepted or owned as personally important.

According to Ryan and Deci's definition (2000), intrinsically motivated behaviours are absolutely unalienated and completely authentic and are "prototype of self-determined actions, stem from the self" (p.343). However, it is worth noting that SDT recognises that extrinsically motivated actions can also become self-determined. Through internalisation and integration individuals can become both extrinsically motivated, committed and authentic.

Differences in the type of extrinsic motivation are associated with different experiences and outcomes (Ryan and Connell, 1989 as in Ryan and Deci, 2000). For example, in one study, the more students were externally regulated the less they showed interest, value, and effort toward achievement and the more they tended to blame others for negative outcomes. Introjected regulation was related to higher anxiety, while identified regulation was associated with more interest and satisfaction. In the same way, studies have shown that more autonomous forms of extrinsic motivation were associated with greater creativity (Amabile, 1982), more cognitive flexibility (Benware and Deci, 1984), higher performance (Miserandino, 1996), higher quality learning (Grolnick and Ryan, 1987), better teacher ratings (Hayamisu, 1997), and higher satisfaction and trust (Deci et al., 1989), among other outcomes (cited from Gagné and Deci, 2005).

The intrinsic motivation of individuals is generally defined broadly as the activity people will engage in without external inducement (Malone and Lepper, 1987). Intrinsically motivated people will engage in activities without looking for a reward, 
other than the enjoyment or the sense of pride or justice that comes with doing the activity. Some theorists see intrinsic motivation more narrowly, as motivation to engage in activities that enhance or maintain a person's self-concept (Purkey and Schmidt, 1987; Purkey and Stanley, 1991). The concept has been very widely used in pedagogy research, to explain the behaviour of students, and their involvement in educational activities (Lepper and Hodell, 1989), but the organisational behaviour literature has been using it increasingly lately (Amabile et al., 1994).

The preceding section reviews SDT in an effort to justify its inclusion in the research and practice of international human resource management. Specifically, looking at the motivation of individuals offers a new and useful perspective on selecting the best candidates for international assignments. We acknowledge the distinction between intrinsic, extrinsic and autonomous, controlled forms of motivation, but we do not appoint any value judgment on either. On the contrary, our model proposes that the best fit depends on organisational-level variables. We thus propose examining the international strategies of firms in transitional economies, to understand the contextual variables which moderate the level of expatriate adjustment.

\subsection{Multinational strategies for subsidiaries in transitional economies: local and global dynamics}

In this section, we introduce the notion of international corporate strategy, and distinguish between local and global strategic orientations at the subsidiary level. We also bridge levels of analysis, from the individual, to the organisation. Specifically, our focus shifts to the subsidiary of the MNE. Notions of global and local are not new in the international management stream. Scholarly work in this area focuses on explaining how multinationals respond to pressures from their environment (Bartlett and Ghoshal, 1998; Doz and Prahalad, 1993). Nevertheless, the international human resource management research does not traditionally focus on much attention on the strategic orientation of the MNE.

As we build theory, we rely primarily on the conceptualisation of local and global dynamics in emerging countries as developed by Marcotte et al. (2010). According to Marcotte et al. (2010), strategies of MNE subsidiary differ depending on the level of adaptation to the local environment. As such, subsidiaries may implement strategies of adaptation to local constraints of emerging markets (local), or strategies of integration with their global operations (global). Local strategies are built on institutional paradigm (Scott, 2001; Westney, 1993), where managers are forced to contend with multiple logics determined by the cultural context. Managers are hard-pressed to learn about their local environment if they wish to compete, and often, learning is done through isomorphism. Conversely, Marcotte et al. (2010) see the global orientation as grounded primarily in an economic logic (Levitt, 1983; Ohmae, 1990) with managers acting as rational actors, emphasising the dominant models from their home countries.

The key distinction between the approach we use here and that proposed by Bartlett and Ghoshal (1998) and Doz and Prahalad (1993) is our focus on strategy at the subsidiary level, which acknowledges that the MNE may use local strategies in some subsidiaries, and global strategies in others. Focusing on the international strategy orientation at the level of the subsidiary allows us to understand why organisations treat their subsidiaries differently, with respect to autonomy, resource allocation, and control (Ratiu and Molz, 2010). While the notion of transnational strategy conveniently lumps 
local and global strategies, it also take away a necessary nuance needed to better understand how MNEs operate, especially when distinguishing between mature and transitional markets.

We agree with Grainger and Nankervis (2001), that globalisation has complicated traditional approaches to human resource management. The authors argue that globalisation has created the need to generate new human resource strategies and practices, along with new skills of employees. Building on their argument, we propose several dimensions that allow us to distinguish between local and global international strategy orientations at the subsidiary level. Table 1 highlights these distinctions. As such, at the level of the global subsidiary, the strategic objective is primarily fitting standardised processes in a global supply chain where products and services do not differ much from country to country. To carry out this objective, the subsidiary relies on rules developed at the MNC level. Managers' role is to ensure that these rules are communicated, and understood. The manager's toolbox is understood to contain comprehensive knowledge of the corporation, through the interpretation of headquarters. At the individual level, expatriate managers are motivated to take on this assignment by the prospect of career advancement.

Table 1 Key distinctions between international corporate strategies

\begin{tabular}{lcc}
\hline & Global & Local \\
\hline Objective & Standardisation & Adaptation \\
Importance of & MNC rules & Local norms \\
Currency & HQ knowledge & Local knowledge \\
Motivation & Career advancement & Learning opportunity \\
\hline
\end{tabular}

Conversely, the local strategy orientation of subsidiaries emphasises adaptation tot he local environment in an offering of goods and services which may differ substantially from those offered by the MNE in other countries. As such, local norms are of critical importance, and the manager's toolbox is built around the acquisition of local knowledge about the host country environment. The expatriate's principal motivation to embark on such assignment is to learn.

To conclude, in this section we introduced international strategy orientation at the subsidiary level as organisational-level variables that moderate the relationship between individual motivation and expatriate adjustment. In the next section, we develop a model that explains how these relationships are expected to form.

\section{Theory development}

How do expatriate's motivation interact with international strategy orientation to influence adjustment to assignments? We investigate the mechanics in which these relationships are expected to develop, based on our firm belief that more can be learned if we bridge what we know of individual's behaviour, with our understanding of multinationals strategies in emerging countries. Figure 2 visually represents the expected interactions between individual- and organisational-level variables. 
Figure 2 Expatriate adjustment across levels

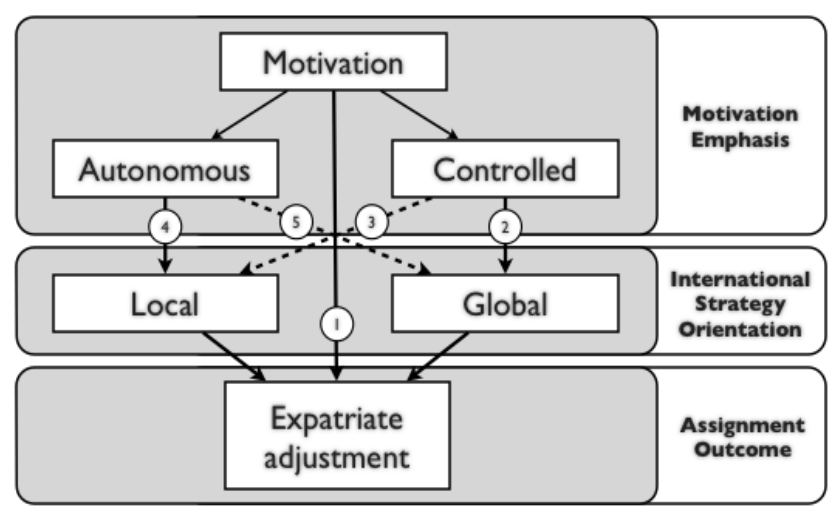

\subsection{Motivation and expatriate adjustment}

Although the educational literature generally makes a value statement by arguing that autonomous is preferred to controlled motivation, this paper does not distinguish between these dimensions of motivation in terms of one being superior to the other. Instead, we acknowledge that individuals vary in their motivations when approaching international assignments, and allow that both autonomous and controlled individuals can have an effective adjustment. A similar conciliatory approach was undertaken by Bénabou and Tirole (2003), where intrinsic and extrinsic motivations were examined through the notion of incentives, from economic theory. They conclude that both types of motivational elements are useful in understanding the use of incentives and rewards in organisations.

In the previous section we have argued the necessity to see motivation as valid antecedent to expatriate adjustment and supports the argument that motivation and expatriate adjustment are related. This relationship exists because the expatriate managers are placed in a new environment with a whole new set of contextual factors, in which, their motivation to act, adjust, and survive regulates their commitment to the successful of that assignment. We therefore offer the following:

Proposition 1 Individual motivation regarding an international assignment will have an effect on the adjustment of expatriates.

\subsection{A typology of expatriate adjustment}

The relationship between motivational variables and expatriate adjustment has some moderating elements. Figure 2 shows the proposed model of moderation between these variables. In it, global or local strategies are posited to influence the strength of the motivation-adjustment relationship. Specifically, we suggest that motivation and strategy interact to provide an ideal type or fit, which impact staffing choices at the subsidiary level. As such, controlled motivation leads managers to adjust more effectively in organisations that employ a global strategic orientation, while 
autonomously motivated managers will have an optimal adjustment in organisations that enact local strategies.

As we have seen earlier, SDT suggests that autonomous motivation is associated with individuals seeking circumstances where there is great uncertainty, and where they are expected to learn and acquire new information about their setting. These managers may fit the expatriate assignment where context is demanding, and the rewards are often difficult to quantify. The best fit for these situations are managers that draw satisfaction from continuous learning, and solving new problems. Controlled motivation has been conceptualised in terms of rewards, and it is used to define individuals who get involved in certain activities because of external validation. Pintrich and Schunk (2002) see that controlled motivation is usually prevalent when individuals engage in activities as means to an end. Accordingly, extrinsically motivated individuals get involved in activities because they believe participation will result in rewards, praise, or avoidance of punishment. These are all external elements of their contextual framework. Consequently, extrinsically motivated managers are expected to adjust better in settings where there is clarity in their tasks, where not much changes in their job description, and where the learning required of them is kept to a minimum. The predictability associated with the assignment is an important feature for the extrinsically motivated manager, because she can plan ahead, and weigh the work versus the rewards as she decides whether to pursue this opportunity.

Figure 3 visually represents a typology of expatriate adjustment profiles that emerges when linking the individual motivation emphasis (autonomous and controlled) and the international strategy orientation. Based on the two factors outlined above, we suggest an ideal type that matches autonomous motivation with local strategic orientation, and controlled motivation with global strategies. We conversely suggest a poor fit if the reverse is true.

Figure 3 A typology of expatriate adjustment profiles

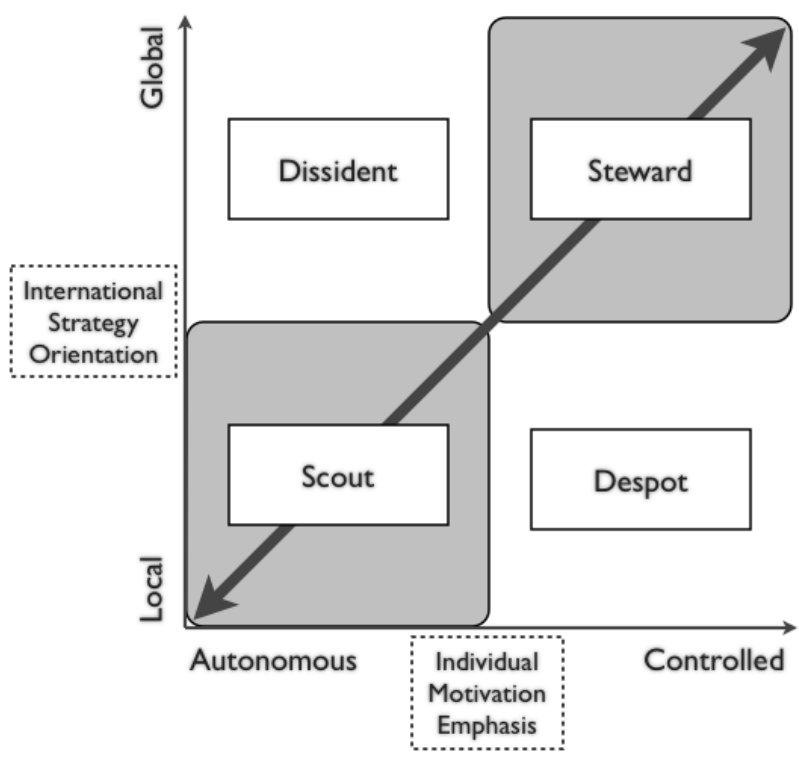




\subsection{Steward or dissident: the influence of global strategies}

As we have seen, global strategies are seen as beneficial in globalised markets (Levitt, 1983). Employing global strategies enhances competitivity through economies of scale. Organisations are able to move through systems easily, and implement strategies uniformly across the subsidiaries (Ohmae, 1990). Strategic decision making belongs at the headquarters of the organisation, and the subsidiaries are generally responsible of the execution of decisions and subsidiaries have little input. In an effort to obtain cost benefits from globalisation, organisations standardise operations as much as they can.

The standardisation also facilitates expatriate assignments, because managers do not have to learn the way the host organisation works as they move from one place to the next; they can slip into their managerial role quickly and, at least in theory, the adjustment to the new work conditions can be minimised. Through global strategies, the organisation ensures that the situational factors are controlled for, such that managers' adjustment period is reduced. Furthermore, the role of the subsidiary manager is to ensure consistency in the implementation of decisions between headquarters and subsidiaries. There is minimum concern to the local institutional dynamics: the interaction with the host country is not seen as useful.

As such, the controlled motivated managers will adjust well in an organisation that adopts a global strategic orientation, because the amount of adaptation and learning required are minimal. The manager can plan and decide whether to accept the assignment or not, fully knowing what to expect during the assignment. The decision is made not based on the learning opportunities but based on the balance between workload, rewards, and opportunity costs of work and non-work factors.

Conversely, the autonomously motivated manager will have a difficult time in an organisation that emphasised rules and relationship with headquarter, and allows little autonomy to develop and explore the richness of the local environment. We should expect that autonomous motivation will act against the individual whose interest in learning is met with a rule that emphasised the opposite.

Therefore, in the context of a global strategic orientation, the manager who possess controlled motivation will function as a steward for the MNE, ensuring that standardised processes are maintained, whereas the autonomously motivated managers will act as dissidents, given that their interests are not met with such assignment. We therefore offer the following:

Proposition 2 In organisations employing global strategies, expatriates with controlled motivation will adjust more effectively.

Proposition 3 In organisations employing global strategies, expatriates with autonomous motivation will adjust ineffectively.

\subsection{Scout or despot: the influence of local strategies}

As we have seen, local strategies are generally associated with multidivisional organisations, where the subsidiaries are granted a larger degree of control in making important strategic decisions (Doz and Prahalad, 1993). The headquarters are mainly involved in giving direction and validating decisions. The subsidiaries are generally independent, and carry out their activities with limited intervention from headquarters in most of the functional areas. Most of the input comes from within the subsidiary and the 
managers have an important role in evaluating options, creating scenarios, and deciding (Oliver, 1991). Furthermore, the locally managed organisation is usually more responsive to the institutional environment and dynamics. The interaction with the host country is seen as very useful for the organisation. As such, the managers of subsidiaries have an important role in maintaining the organisation locally responsive.

We suggest that autonomously motivated managers will adjust well in the organisation that adopts local strategy orientation, because the assignment generally emphasises adaptation, and the acquisition of local knowledge. The manager is no longer required to see through standardised processes. We have also seen that the autonomously motivated manager does not operate based on external rewards. While rewards are important, and adjustment (especially for the non-work dimensions of the construct) is generally facilitated by an appropriate compensation and perquisites package, the decision to undertake the assignment does not rest on rewards for the intrinsically motivated manager. When evaluating the assignment, the autonomously motivated manager will seek learning opportunities. This type is perhaps best associated with the notion of explorer or scout, who is sent in a thick institutional environment to learn and to adapt.

Conversely, we expect the manager exhibiting controlled motivation to be a poor match for the organisation employing a local strategy orientation. The lack of global, or headquarter mandated rules make for a more flexible, yet much more unstable job description. The reward structure is similarly unclear, and learning opportunities are not a strong incentive for this type. This type is likely going to exhibit characteristics similar to those of a despot, especially if put in a position of power within the subsidiary.

Building on the international strategy orientation and motivation emphasis we offer the following:

Proposition 4 In organisations employing local strategies, expatriates with autonomous motivation will adjust effectively.

Proposition 5 In organisations employing local strategies, expatriates with controlled motivation will adjust ineffectively.

\section{Discussion and conclusions}

In this paper, we proposed a model that introduces motivation variables from SDT as antecedents to the adjustment of expatriates. We justified the necessity of this addition and supported with a discussion that links the literature on motivation to that on international human resource management. We also introduced a moderating variable - international strategy orientation at the level of the subsidiary - arguing that the link between motivation and adjustment will depend on the type of strategy employed.

The model suggests that international human resource management literature can gain from a model that crosses levels of analysis, thus offering a more comprehensive explanation, and providing a fresh look at the link between individual-level antecedents, and firm-level moderators. This paper offers a new lens to view the relationship between motivation and expatriate adjustment. Strong confirmatory findings from future empirical studies testing these propositions would imply that theories of expatriate adjustment could benefit by examining different antecedents than the usual suspects, especially since 
mixed results have been found with personal characteristics and other similar antecedents. Such findings would also imply that there is value in bridging a disciplinary gap between international human resource management and international strategic management. The multilevel approach answers recent calls from researchers to broaden our view in examining complex multinational organisations.

For practice, these findings would suggest that organisations can improve success of the expatriate adjustments if attention is given to motivational variables in conjunction with the strategic context of the organisation. Confirmed results would suggest that in multidivisional, locally responsive organisations autonomous motivation is key to effective adjustment. Similarly, in large global organisations, controlled motivation would offer a more effective adjustment.

\section{References}

Amabile, T.M. (1982) 'Social psychology of creativity: a consensual assessment technique', Journal of Personality and Social Psychology, Vol. 43, pp.997-1013.

Amabile, T.M., Hill, K.G., Hennessey, B.A. and Tighe, E.M. (1994) 'The work preference inventory: assessing intrinsic and extrinsic motivational orientations', Journal of Personality and Social Psychology, Vol. 66, No. 5, pp.950-967.

Aycan, Z. (1997) 'Acculturation of expatriate managers: a process model of adjustment and performance', in D.M. Saunders and Z. Aycan (Eds.): New Approaches to Employee Management, pp.1-40, JAI Press, Greenwich, CT.

Bartlett, C.A. and Ghoshal, S. (1998) Managing Across Borders: The Transnational Solution, Harvard Business School Press, Boston, MA.

Bénabou, R. and Tirole, J. (2003) 'Intrinsic and extrinsic motivation', Review of Economic Studies, Vol. 70, pp.489-520.

Benware, C. and Deci, E.L. (1984) 'Quality of learning with an active versus passive motivational set', American Educational Research Journal, Vol. 21, pp.755-765.

Black, J.S. (1990) 'The relationship of personal characteristics with adjustment of Japanese expatriate managers', Management International Review, Vol. 30, pp.119-134.

Black, J.S. and Stephens, G.K. (1989) 'The influence of the spouse on American expatriate adjustment and intent to stay in Pacific Rim overseas assignments', Journal of Management, Vol. 15, pp.529-544.

Caligiuri, P.M. (2000) 'The big five characteristics as predictors of expatriate's desire to terminate the assignment and supervisor-rated performance', Personnel Psychology, Vol. 53, pp.67-88.

Caligiuri, P.M., Hyland, M.M., Joshi, A. and Bross, A.S. (1998) 'Testing a theoretical model for examining the relationship between family adjustment and expatriates’ work adjustment', Journal of Applied Psychology, Vol. 83, pp.598-614.

Caligiuri, P.M., Lazarova, M. and Tarique, I. (2001) 'The performance goals of expatriate assignments: using assignment categories to determine selection, cross-cultural training, and repatriation practices', Paper presented at the Academy of Management Annual Meetings, Washington, DC.

Chen, G., Kirkman, B.L., Kim, K., Farh, C.I.C. and Tangirala, S. (2010) 'When does cross-cultural motivation enhance expatriate effectiveness? A multilevel investigation of the moderating roles of subsidiary support and cultural distance', Academy of Management Journal, Vol. 53, No. 5, pp.1110-1130.

Deci, E.L. (1975) Intrinsic Motivation, Plenum, New York.

Deci, E.L. (1992) 'On the nature and functions of motivation theories', Psychological Science, Vol. 3, pp.167-171. 
Deci, E.L. and Ryan, R.M. (1980) 'The empirical exploration of intrinsic motivational processes', in L. Berkowitz (Ed.): Advances in Experimental Social Psychology, Vol. 13, pp.39-80, Academic Press, New York.

Deci, E.L. and Ryan, R.M. (1985a) Intrinsic Motivation and Self-determination in Human Behavior, Plenum, New York.

Deci, E.L. and Ryan, R.M. (1985b) 'The general causality orientations scale: self-determination in personality', Journal of Research in Personality, Vol. 19, pp.109-134.

Deci, E.L. and Ryan, R.M. (2000) 'When rewards compete with nature: the undermining of intrinsic motivation and self-regulation', in C. Sansone and J.M. Harackiewicz (Eds.): Intrinsic and Extrinsic Motivation: The Search for Optimal Motivation and Performance, pp.13-54, Academic Press, San Diego, CA.

Deci, E.L., Connell, J.P. and Ryan, R.M. (1989) 'Self-determination in a work organization', Journal of Applied Psychology, Vol. 74, pp.580-590.

DeValk, P. (2004) 'The global mobile workforce building productive expatriate assignments', Workspan, Vol. 40-42.

Doz, Y. and Prahalad, C.K. (1993) 'Managing DMNCs: a search for a new paradigm', in S. Ghoshal and D. Westney (Eds.): Organization Theory and the Multinational Corporation, pp.24-50, St. Martin's Press, New York.

Feldman, D.C. and Bolino, M.C. (1999) 'The impact of on-site mentoring on expatriate socialization: a structural equation modeling approach', International Journal of Human Resource Management, Vol. 10, pp.54-71.

Gagné, M. and Deci, E.L. (2005) 'Self-determination theory and work motivation', Journal of Organizational Behavior, Vol. 26, pp.331-362.

Gerhart, B. (2005) 'Human resources and business performance: findings, unanswered questions, and an alternative approach', Management Revue, Vol. 16, No. 2, pp.174-185.

Grainger, R.J. and Nankervis, A.R. (2001) 'Expatriation practices in the global business environment', Research and Practice in Human Resource Management, Vol. 9, No. 2, pp.77-92.

Grolnick, W.S. and Ryan, R.M. (1987) 'Autonomy in children's learning: an experimental and individual difference investigation', Journal of Personality and Social Psychology, Vol. 52, pp.890-898.

Harrison, D.A., Shaffer, M.A. and Bhaskar-Shrinivas, P. (2004) 'Going places: roads more and less traveled in research on expatriate experiences', in Joseph Martocchio, Hui Liao and Aparna Joshi (Eds.): Research in Personnel and Human Resources Management, Volume 23, pp.199-247, Emerald Group Publishing Limited.

Kraimer, M.L. and Wayne, S.J. (2004) 'An examination of perceived organizational support as a multidimensional construct in the context of an expatriate assignment', Journal of Management, Vol. 30, No. 2, pp.209-237.

Kraimer, M.L., Wayne, S.J. and Jaworski, R. (2001) 'Sources of support and expatriate performance: the mediating role of expatriate adjustment', Personnel Psychology, Vol. 54, No. 1, pp.71-99.

Lazarova, M. and Caligiuri, P.M. (2001) 'Retaining repatriates: the role of organizational support practices’, Journal of World Business, Vol. 36, pp.389-401.

Lepper, M.R. and Hodell, M. (1989) 'Intrinsic motivation in the classroom', in C. Ames and R. Ames (Eds.): Research on Motivation in Education: Goals and Cognitions, Academic Press, New York.

Levitt, T. (1983) 'The globalization of markets', Harvard Business Review, May-June, pp.92-102.

Malone, T.W. and Lepper, M.R. (1987) 'Making learning fun: a taxonomy of intrinsic motivations for learning', in R.E. Snow and M.J. Farr (Eds.): Aptitude, Learning, and Instruction, III: Cognitive and Affective Process Analysis, pp.223-253, Lawrence Erlbaum Associates, Hillsdale, NJ. 
Marcotte, C., Soussi, S.A., Molz, R., Farashahi, M. and Hafsi, T. (2010) 'Strategy implementation in emerging countries: three theoretical approaches', in Molz, R., Ratiu, C. and Taleb, A. (Eds.): The Multinational Enterprise in Developing Countries: Local versus Global Logic, pp.7-18, Routledge, New York.

McGinley, J. (2008) 'Expatriate adjustment within a social context: examination of a sample in Russia', Journal of Social, Evolutionary, and Cultural Psychology, Vol. 2, No. 2, pp.56-68.

Miserandino, M. (1996) 'Children who do well in school: individual differences in perceived competence and autonomy in above-average children', Journal of Educational Psychology, Vol. 88, pp.203-214.

Ohmae, K. (1990) The Borderless World: Power and Strategy in the Interlinked Economy, Free Press, New York.

Oliver, C. (1991) 'Strategic responses to institutional processes', Academy of Management Review, Vol. 16, No. 1, pp.145-179.

Pintrich, P.R. and Schunk, D.H. (2002) Motivation in Education: Theory, Research, and Applications, Merrill/Prentice Hall, Upper Saddle River, NJ.

Purkey, W.W. and Schmidt, J.J. (1987) The Inviting Relationship: An Expanded Perspective for Professional Counseling, Prentice-Hall, Englewood Cliffs, NJ.

Purkey, W.W. and Stanley, P.H. (1991) Invitation Teaching, Learning, and Living, NEA Professional Library, National Education Association, Washington, DC.

Ratiu, C. and Molz, R. (2010) 'Multinationals and corporate environmental strategies: fostering subsidiary initiative', in Molz, R., Ratiu, C. and Taleb, A. (Eds.): The Multinational Enterprise in Developing Countries: Local versus Global Logic, pp.179-193, Routledge, New York.

Rugman, A.M. (2001) The End of Globalization, Random House, London.

Ryan, R.M. (1995) 'Psychological needs and the facilitation of integrative processes', Journal of Personality, Vol. 63, No. 3.

Ryan, R.M. and Deci, E.L. (2000) 'Self-determination theory and the facilitation of intrinsic motivation, social development, and well-being', American Psychologist, pp.68-78.

Ryan, R.M., Connell, J.P. and Deci, E.L. (1985) 'A motivational analysis of self-determination and self-regulation in education', in C. Ames and R.E. Ames (Eds.): Research on Motivation in Education: The Classroom Milieu, pp.13-51, Academic Press, New York.

Sanchez, J.I., Spector, P.E. and Cooper, C.L. (2000) 'Adapting to a boundaryless world: a developmental expatriate model', Academy of Management Executive, Vol. 14, pp.96-106.

Scott, R.S. (2001) Institutions and Organizations, 2nd ed., Sage Publications, Thousand Oaks.

Shaffer, M.A. and Harrison, D.A. (1998) 'Expatriates’ psychological withdrawal from international assignments: work, non-work, family influences’, Personnel Psychology, Vol. 51, pp.87-118.

Shaffer, M.A., Harrison, D.A. and Gilley, K.M. (1999) 'Dimensions, determinants, and differences in the expatriate adjustment process', Journal of International Business Studies, Vol. 30, pp.557-581.

Shaffer, M.A., Harrison, D.A., Gilley, K.M. and Luk, D.M. (2001) 'Struggling for balance amid turbulence on international assignments: work--family conflict, support and commitment', Journal of Management, Vol. 27, pp.99-121.

Torbion, I. (1982) Living Abroad, Wiley, New York.

Tung, R.L. (1981) 'Selection and training personnel for overseas assignments', Columbia Journal of World Business, Vol. 16, pp.21-25.

Westney, D.E. (1993) 'Institutionalization theory and the multinational corporation', in S. Ghoshal and D.E. Westney (Eds.): Organization Theory and the Multinational Corporation, pp.53-76, St. Martin's Press, New York.

Williams, G.C. and Deci, E.L. (1996) 'Internalization of biopsychosocial values by medical students', Journal of Personality and Social Psychology, Vol. 70, pp.767-779. 